\title{
A Strategic Investigation for Fuel Economy Improvement of Medium-Duty Tactical Truck: Preliminary Simulation and Experimental Results
}

\author{
Y. Gene Liao ${ }^{1}$ and Allen M. Quail Jr. ${ }^{2}$ \\ ${ }^{1}$ Engineering Technology Department, Wayne State University, 4855 Fourth Street, Detroit, MI 48202, USA \\ ${ }^{2}$ CAE Department, ASRC-WTSI, Inc., 2301 West Big Beaver Road, 921, Troy, MI 48084, USA
}

Correspondence should be addressed to Y. Gene Liao, geneliao@wayne.edu

Received 22 February 2011; Accepted 11 April 2011

Academic Editors: Y. Chen and Y. He

Copyright ( 2011 Y. G. Liao and A. M. Quail Jr. This is an open access article distributed under the Creative Commons Attribution License, which permits unrestricted use, distribution, and reproduction in any medium, provided the original work is properly cited.

\begin{abstract}
This paper reports the planning efforts and preliminary results of increasing fuel economy in the current fleet of medium-duty tactical truck. A strategic plan was developed through investigation of current and future technology offerings from original equipment manufacturers and after market suppliers. Research efforts consisted of an initial phase where a broad range of integration candidates were collected and a secondary phase where in-depth analysis was conducted to target those to be considered for inclusion in the strategic plan. The strategic plan lays out the integrated technologies in the near term including auxiliary electrification of engine cooling fan and hydrogen injection. For the mid-term time frame, the plan involves implementing an engine stop/start system and electrifying other auxiliaries. The final step in the plan is the development and implementation of a full hybrid population. The preliminary results include simulation of the electric cooling fan and mild hybrid powertrain, and experimental test of hydrogen injection.
\end{abstract}

\section{Introduction}

The U.S. Government owns and maintains a large fleet of ground vehicles covering a wide spectrum of mission profiles. The cost to supply each vehicle with fuel during peace time is staggering and becomes more so under war zone conditions. The fuel represents more than half of the logistics tonnage of the Department of Defense (DoD), and more than $70 \%$ of the tonnage required to put the U.S. Army into position for battle [1]. The DoD estimates that 40000 Army personnel involved in either the distribution or movement of energy [2]. Not to mention only two out of the top ten battlefield fuel consumers in the U.S. Army are combat vehicles and the other eight carry fuel and supplies. Over half of the fuel transported to the battlefield is consumed by support vehicles, not vehicles engaged in frontline combat [3]. The impact of the vehicle fuel economy in military applications is amplified due to the fact that much of the present logistics support is devoted to moving fuel. It is critical to improve the fuel economy of those vehicles that play an important role in the U.S. Army tactical vehicle fleet.

The Family of Medium Tactical Vehicles (FMTV) has 14 variations of 2.5-ton and 5-ton truck, and continues to be the highest percent availability of any vehicle in the U.S. Army tactical vehicle fleet [4]. The most common version of the FMTV is the Light Medium Tactical Vehicle (LMTV), a high mobility, 2.5-ton class, payload, $4 \times 4$ diesel-powered truck as shown in Figure 1 [5]. Basically, the LMTVs perform unit mobility and supply missions including the transport of equipment and personnel. The vehicle specifications are listed in Table 1 [6]. Commonality of chassis and power train components between the vehicles in the LMTV allow improvements to the target vehicle to have the potential to benefit the entire fleet.

The focus of this work is the feasibility analysis and evaluation of current and future technology offerings from original equipment manufacturers and aftermarket suppliers 
that improve the fuel economy of the LMTV M1078 A1 2.5ton cargo trucks. A strategic plan was developed that layouts the integrated technologies in the near-term, mid-term, and long-term time frame for fuel economy improvement of the truck. This paper reports the strategic plan and preliminary results of the work. The preliminary results include (1) establishment of a validated, high fidelity baseline analytical vehicle model, (2) modelling and simulation of the electrified engine cooling fan and mild hybrid power train system, and (3) experimental investigation of the influence of hydrogen injection on the fuel economy.

\section{Strategic Plan Development}

Investigation activities consisted of an initial phase where a broad range of integration candidates were collected. To capture items discovered through the investigation, a database was created to track all potential products and technologies. The database contained criterion to compare products based upon their Technology Readiness Level (TRL) as defined by the 2007 Army Science \& Technology Master Plan [7], ease of installation, maintenance requirements, the return on investment and potential fuel economy improvement. Each technology was evaluated on its technical merits with consideration given to the needs and strategic goals of government agencies. Additional consideration was given to technologies previously or currently being studied by others government agencies to avoid duplicate tasks. Based on the analytical results of the database, a strategic plan was developed where in-depth analysis was conducted to target those to consider for inclusion in the plan.

\subsection{Investigation Focus Areas. As part of the U.S. Department} of Energy (DoE) 21st Century Truck Program, investigation of an M1078 found that only about 18\% of the fuel energy put into the tank is used to move the vehicle down the road. The rest is lost through mechanical, frictional and aerodynamic inefficiencies as indicated in Figure 1 [5]. The investigation focus areas are placed on the areas of aerodynamics, structure design, lightweight materials, vehicular electronics, and power train efficiency and hybridization. Current government research initiatives target significant fuel economy improvements with no degradation to vehicle mobility or payload capacity. Opportunities for aerodynamic drag reduction, mass reductions, and additional features of vehicular electronics as a means for gaining fuel economy were determined to be limited due to the nature of the vehicle life cycle. Therefore, electrified auxiliary functions and advanced hybrid power train systems were identified as critical components of the strategic plan.

2.1.1. Aerodynamics and Structure Design. Vehicle aerodynamics are comprised of several factors including downforce, lift, yawing movement and noise. Research was focused on reducing the coefficient of drag due to its direct correlation to fuel economy. Drag at its simplest can be defined as a force that resists the movement of a solid body through air and is directly related to a vehicle's shape. Vehicles with smoother
TABLE 1: LMTV M1078 A1 vehicle description [6].

\begin{tabular}{|c|c|}
\hline Wheel base & $3900 \mathrm{~mm}\left(153.5^{\prime \prime}\right)$ \\
\hline $\begin{array}{l}\text { Vehicle curb weight } \\
\text { (no kits, crew, fuel) }\end{array}$ & $7809 \mathrm{~kg}(17216 \mathrm{lb})$ \\
\hline Payload & $2268 \mathrm{~kg}(5000 \mathrm{lb})$ plus kits \\
\hline Towed load & $5443 \mathrm{~kg}(12000 \mathrm{lb})$ \\
\hline $\begin{array}{l}\text { Maximum speed } \\
\text { (governed, at gross } \\
\text { weight) }\end{array}$ & $94 \mathrm{~km} / \mathrm{h}(58 \mathrm{mph})$ \\
\hline $\begin{array}{l}\text { Range: } 58 \text { gal }(219 \mathrm{~L}) \\
\text { nominal }\end{array}$ & $645+\mathrm{km}(400+\mathrm{mi})$ \\
\hline $\begin{array}{l}\text { Maximum grade/side } \\
\text { slope }\end{array}$ & $60 \% / 30 \%$ \\
\hline Engine & $\begin{array}{l}\text { Caterpillar C7 ATAAC (air-to-air after } \\
\text { cooler) HD diesel, in-line 6-cylinder, } \\
\text { 4-stroke-cycle. }\end{array}$ \\
\hline Displacement & $7.2 \mathrm{~L}(441 \mathrm{cu}$ in $)$ \\
\hline Aspiration & $\begin{array}{l}\text { Turbocharged, air-to-air after cooler, EPA } \\
07 \text { certified. }\end{array}$ \\
\hline Rating & 205 kW (275 hp)@ 2600 rpm \\
\hline Torque & 1,166 Nm (860lb-ft)@1440 rpm \\
\hline Fuel types & Diesel, DF-2, JP-4, JP-8, VV-F-800. \\
\hline Transmission & $\begin{array}{l}\text { Allison } 3700 \text { SP, fully automatic/select } 7 \\
\text { speed, electronically controlled, full-time } \\
\text { all-wheel drive. }\end{array}$ \\
\hline Front wheels & $30 \%$ torque \\
\hline Rear wheels & $70 \%$ torque \\
\hline Overall axle gear ratio & $7.8: 1$ \\
\hline
\end{tabular}

shapes expend less energy moving air out of their way as they travel. A study by the Transportation Research Board found that cutting resistance by $10 \%$ yielded a $1-2 \%$ improvement in fuel economy [8]. In established vehicle fleets, managing architectural gaps and joints can translate directly to fuel consumption reductions. There are many OEM's offering products to reduce aerodynamic drag that can be integrated in a short time frame. Most of these are easy to install, require minimal maintenance and are used everyday. However they are predominantly designed with Class 8 vehicles traveling at highway speeds in mind. Speed is an important part of the drag equation. At $112.6 \mathrm{~km} / \mathrm{h}(70 \mathrm{mph})$, a vehicle has four times the force working against it than at $56.3 \mathrm{~km} / \mathrm{h}(35 \mathrm{mph})$ [9]. Given that the top speed of the M1078 is $94 \mathrm{~km} / \mathrm{h}$ $(58 \mathrm{mph})$ and its average operating speed is much lower, minimal fuel economy gains are estimated.

2.1.2. Lightweight Materials. Traditionally, material science advancements have been driven by the aerospace industry's necessity for lightweight materials that are able to perform under increasingly demanding conditions with no degradation in performance. These advanced materials, through their potential to reduce vehicle weight, can play an integral role in increasing fuel economy and reducing harmful emissions. Research has shown that a $10 \%$ reduction in vehicle mass without re-sizing the diesel power train correlates to upwards of 3.4\% fuel economy gains [10]. A specific goal of 


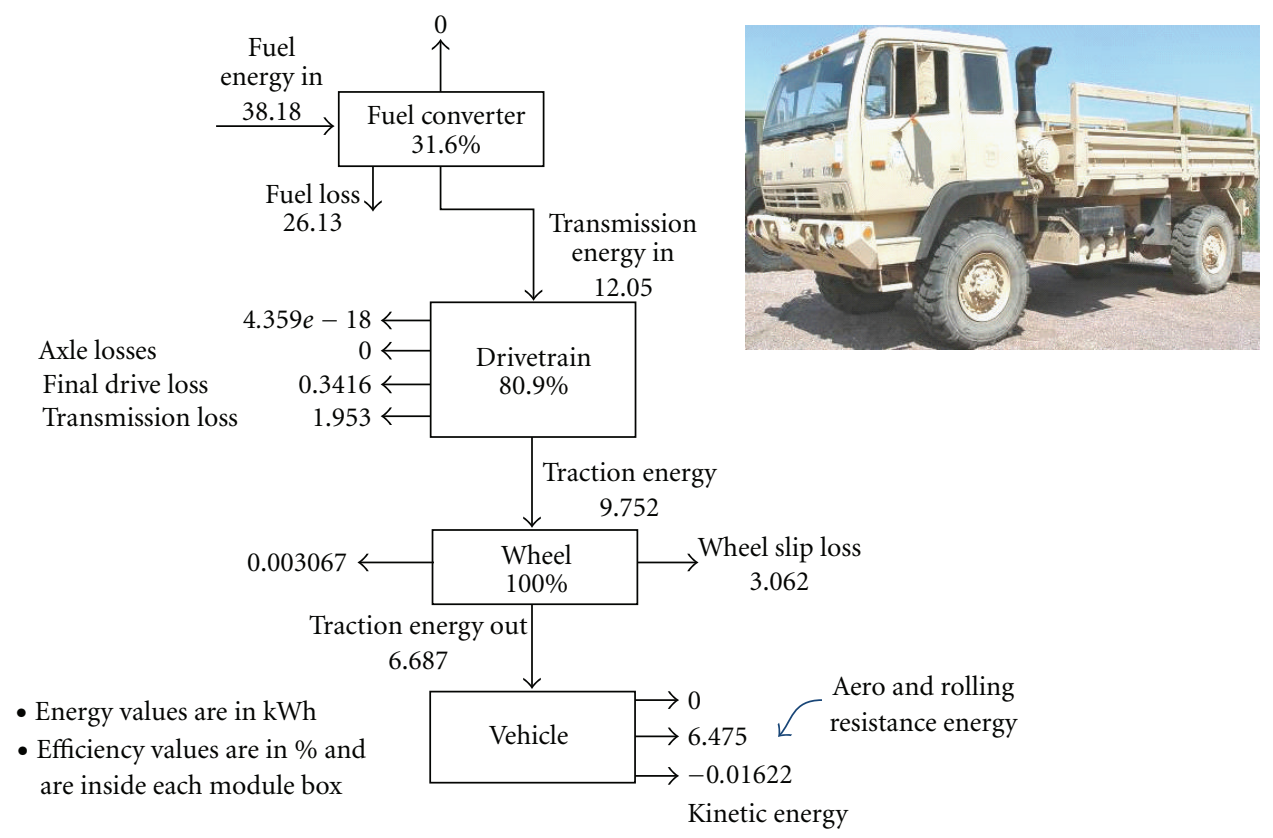

Figure 1: Energy balance of the M1078 [5].

the DoE's 21st Century Truck Partnership is to develop and demonstrate materials and manufacturing processes that will facilitate a $15-20 \%$ tare weight reduction in heavy vehicles by 2012 [5].

Research efforts have uncovered technologies at various readiness levels. For example, a cargo bed design was developed using composite materials that would represent a potential weight reduction of $515 \mathrm{Kg}$ without compromising performance. Composite leaf springs are also available that are lighter in weight than the standard steel springs. There are also products available composed of materials that will help reduce fuel consumption. Lear Corporation has developed seat foam that is a blend of $40 \%$ soy and $60 \%$ petroleum products [11]. In addition to reducing the over $13.6 \mathrm{~kg}$ of petroleum-based foams found in most vehicles, production of these materials emits less carbon dioxide into the atmosphere. Several companies have developed materials designed to aid thermal management. Glass coatings that reflect infrared rays and reduce heat transferred into the passenger compartment will decrease the amount of energy drawn from the engine typically required for $\mathrm{A} / \mathrm{C}$ operations.

Long-term lightweight material options also hold promise but will involve extensive interaction with vehicle components and design. Some, such as magnesium alloys, that possess desirable strength and weight characteristics, are currently being used to make gearbox castings and other engine components in Formula One race cars. Although currently cost is prohibitive to manufacture, the extreme technical requirements and operating environment of this sport are testament to its integration potential.

2.1.3. Vehicular Electronics. Advancements in electronics have provided many possible avenues to increase vehicle efficiency. Research in support of this project uncovered many technologies that encompass the full range of vehicle systems and readiness levels. Simple integrations include the AUTOTHERM Energy Recovery System [12]. Designed to reduce idle time, it employs a small magnetically coupled electrical pump that automatically turns on when then engine is turned off. The pump circulates heated coolant from the engine to the heater coils to heat the passenger compartment. At an outside temperature of $32^{\circ} \mathrm{F}$, the company estimates that their product will keep the cab of a Class 8 vehicle at $72^{\circ} \mathrm{F}$ for $3-4$ hours while enabling a $6 \%$ reduction in overall fuel consumption. Additional benefits include reduced emissions and vehicle thermal signature, decreased engine damage attributable to heat soak and a relatively low purchase price.

2.1.4. Powertrain Efficiency. As illustrated in Figure 1, M1078 power train modeled at the time of the study was $31.6 \%$ efficient [5]. While newer versions of the vehicle certainly include technologies that have increased this figure, there remains room for improvement. Products designed to further increase efficiency range from plug-and-play programmable engine tuners to radically redesigned power train systems. One interesting product designed to improve fuel economy is the hybrid electric drive system offered by Variable Torque Motor, LLC [13]. Intended for Class 3-6 trucks, the system uses a $42 \mathrm{~kW}$ motor/generator that acts as a magnetic continuously variable transmission by providing variable torque and speed through axial field weakening governed by the controller. The ultracapacitor is used to store energy generated during deceleration that is used at the next acceleration to provide launch assist. When the stored energy is depleted or when the vehicle is on the highway, the permanent magnet in the motor/generator is automatically decoupled from the stator coils to eliminate torque drag. 
The design also allows integration into the existing vehicle power train without major tear-down or installation effort and transfer of the system from one vehicle to another. It is estimated the system will decrease fuel consumption by $25-30 \%$, reduce required brake maintenance by $40-50 \%$ due to regenerative braking capabilities and reduce vehicle emissions. As with most new technologies, cost is an issue.

2.1.5. Powertrain Hybridization. While hybrid technology has advanced radically over the past decade, the focus has been on integration in passenger cars and light-duty trucks. However, recent fuel cost increases have shifted some of this attention to the medium- and heavy-duty truck market. Hybrid vehicles use dual energy sources propulsion system in which energy is used more efficiently than in standard systems. A standard propulsion system has four primary components: (1) the internal combustion engine (ICE) to supply power for the other vehicle systems; (2) the transmission to control the speed ratio and the level of torque multiplication between the engine and the final drive; (3) the final drive and drive axle assembly to multiply transmission output torque and transfer power to the wheel assembly; (4) the tire and wheel assembly that transfers power from the axle assembly to the ground. To hybridize a vehicle propulsion system, electric machines must be connected somewhere in the power flow.

Based on the ratio of electric power to total power of a vehicle, the degree of power train hybridization is typically classified into two levels: mild and full (strong) hybrids. Hybrid systems provide additional control. This additional level of control enables fuel economy increases by: (1) allowing the ICE to be turned off when idling or during periods of low power output - two highly inefficient stages of typical ICE operation; (2) recapturing waste energy through regenerative braking which can be stored for later use; (3) providing launch assist; (4) supplying assist during varying power demand. Additional power from the motor/battery reduces the engine power requirement and allows the potential to down-size the ICE. A smaller engine operates at a higher percentage of its peak capacity more of the time resulting in increased fuel economy.

2.2. Near-Term Integration. Near-term technologies are categorized as being commercial off-the-shelf in nature. They are ready-made, available for sale to the general public, require minimal installation, training and/or maintenance effort, and can be physically integrated into the vehicle in less than three years. Two technologies are recommended for nearterm integration: (1) electrification of engine cooling fan system and (2) the hydrogen fuel injection system.

2.2.1. Engine Cooling Fan Electrification. Conventional engine powered accessories are mechanical belt driven and have limited operational control. This causes the auxiliary functions to operate inefficiently resulting in decreased fuel economy. Table 2 summarizes the accessory power demand of the belt driven components of a medium tactical truck.
TABLE 2: FMTV auxiliary power demand [14].

\begin{tabular}{lc}
\hline Auxiliary & Power demand $(\mathrm{kW})$ \\
\hline Engine cooling fan & 26.0 \\
Power steering & 16.5 \\
Transmission oil pump & 15.0 \\
Engine oil pump & 4.0 \\
A/C compressor & 3.4 \\
Engine cooling pump & 2.0 \\
\hline
\end{tabular}

The current M1078 has a single $660 \mathrm{~mm}$ diameter clutchtype fan which draws $21 \mathrm{~kW}$ to $23 \mathrm{~kW}$ of power from the engine in normal operation and up to $26 \mathrm{~kW}$ at peak operation [14].

To supplement the normal air movement across the radiator core tubes when the vehicle is at stationary or moving very slowly, a fan is positioned on the exit side of the air stream passing through the radiator, that is, between the radiator and the engine. The fan-blade pitch and direction of rotation create a pressure depression on the fan side of the radiator matrix; therefore the air on the inlet side of the radiator will tend to force its way through the radiator core to try to cancel out this variation of pressure. The resultant air movement will thus provide a continuous air stream over the tubes and fins to dissipate the heat being circulated by the coolant. Figure 2(a) shows a schematic diagram of diesel engine with its cooling system.

Information from a $60 \%$ traction effort evaluation conducted on the current M1078 cooling fan system required air flow of approximately 8000 to 15000 Cubic Feet per Minute (CFM) (226 to $425 \mathrm{~m}^{3} /$ minute) at the zero pressure. The applications of electric fans can be arranged in one large single fan or multiple fans, as shown in Figures 2(b) and 2(c). Although multiple fans allow flexible packaging options to maximize air flow and optimize air pressure for increased cooling capabilities, packaging constraint and small electric motor torque has limited the total CFM. Based upon analysis conducted using five $387 \mathrm{~mm}$ diameter electric fans, the system provides a resultant 12580 CFM (2516 CFM of each fan) $\left(356 \mathrm{~m}^{3} /\right.$ minute, $71 \mathrm{~m}^{3} /$ minute per fan) that did not meet the requirement at zero pressure.

The challenging to install single electric fan is the size of fan motor (overall length, rated torque, and rated speed of the motor). Using the same diameter size $\left(d_{\mathrm{fan}}=660 \mathrm{~mm}\right)$ of the current fan, the required motor power is calculated based on the $425 \mathrm{~m}^{3} /$ minute air flow

$$
A_{\mathrm{fan}}=\frac{1}{4} \pi d_{\mathrm{fan}}^{2}=\frac{1}{4} \pi\left(\frac{660}{1000}\right)^{2}=0.342 \mathrm{~m}^{2}
$$

where $A_{\text {fan }}$ is the fan area and $d_{\text {fan }}$ is the diameter of the fan

$$
\begin{aligned}
V_{\mathrm{air}} & =\frac{C F M}{A_{\mathrm{fan}}}=\frac{15000}{3.687}=4068.334 \mathrm{ft} / \mathrm{min} \\
& =67.806 \mathrm{ft} / \mathrm{sec}=20.67 \mathrm{~m} / \mathrm{sec},
\end{aligned}
$$




$$
\begin{aligned}
\mathrm{HP}_{\mathrm{air}} & =A_{\mathrm{fan}} \cdot\left(\frac{p_{\text {air }}}{2}\right) \cdot V_{\text {air }}^{3} \\
& =3.687 \mathrm{ft}^{2} \cdot \frac{1}{2} \cdot 0.079621 \mathrm{lb} / \mathrm{ft}^{3} \cdot(4068.334 \mathrm{ft} / \mathrm{min})^{3} \\
& =85263.3 \mathrm{ft} \cdot \mathrm{lb}_{\mathrm{f}} / \mathrm{min} \\
& =2.59 \text { horsepower } \\
& =1.93 \mathrm{~kW}
\end{aligned}
$$

where $V_{\text {air }}$ is the air flow speed, $p_{\text {air }}$ is air density, and $\mathrm{HP}_{\text {air }}$ is the required horsepower to move the air. The efficiency of the motor is typically 75 to $90 \%$ and the efficiency of the fan may be $70 \%$ to $90 \%$, lower for simple sheet metal blades, higher for twisted blade or blade integral with the hub and small tip clearance. Hence, the required horsepower of electric motor

$$
\mathrm{HP}_{\text {motor }}=\frac{\mathrm{HP}_{\mathrm{air}}}{(0.75 \cdot 0.6)}=5.76 \text { horsepower }=4.29 \mathrm{~kW} \text {, }
$$

where $\mathrm{HP}_{\text {motor }}$ is the electric motor horsepower. A single electric motor with the original fan size can produce the required CFM while it consumes much less power.

2.2.2. Hydrogen Fuel Injection. The use of hydrogen gas to increase fuel economy is becoming more widely accepted. One way to take advantage of the energy density of hydrogen in current diesel engines is to add a small volume of hydrogen gas into the engine air intake. To generate hydrogen onboard a vehicle, electrolysis is typically used to separate hydrogen from oxygen in water. A hydrogen-rich mixture is then introduced into the air volume of the engine intake in a small proportion $(1-3 \%)$ of the total air volume being used by the engine. Once the combustion process takes place, the chemical reaction of the hydrogen and oxygen produce water as byproduct, reducing fuel consumption and $\mathrm{CO}_{2}$ emissions, increasing engine power, and facilitating a more efficient fuel burned in the combustion chamber.

The hydrogen fuel injection is a retrofit system requires no driver-vehicle interface. The system is not at significant pressures as to pose a risk of explosion because there is no large amount of hydrogen stored in the vehicle. The size and weight of the system does not substantially diminish the overall energy gains. However, the energy required for the electrolysis process might lower the fuel economy gains.

2.3. Mid-Term Integration. Mid-term technologies are categorized as being at a prototype level (or better) with demonstrations performed in a relevant or operational environment. They will require moderate installation, training and/ or maintenance effort, and have an integration time frame of between three and eights years. Two arrangements are identified for mid-term integration: (1) an engine stop/start system, and (2) mild hybridization of propulsion system and electrification of other auxiliary functions.

2.4. Long-Term Integration. Long-term technologies are categorized into two groups: (1) those that will need extensive development prior to being considered production ready and (2) those that are new to the commercial market but will require extensive installation, training and/or maintenance effort before they can be considered for LMTV integration. The integration time frame of these is deemed to be greater than eight years. The long-term integration target is an LMTV outfitted as a full hybrid vehicle.

This paper focused on the preliminary results of the near-term technologies that improve fuel economy. The preliminary results include (1) establishment of a validated, high fidelity baseline analytical vehicle model, (2) modelling and simulation of the electrified engine cooling fan and mild hybrid power train system, and (3) experimental investigation of the influence of hydrogen injection on fuel economy.

\section{Analytical Vehicle Model and Experimental Test}

The vehicle modelling and simulation allows the exploration of design-space to study numerous combinations in the fuel economy. Simulation software packages can provide convenience and flexibility for integrating technology and produce evaluated results for different configurations of the vehicle drivetrain. Experimental test was conducted to collect realworld vehicle data to correlate and validate the analytical vehicle model.

3.1. Baseline Vehicle Model. Vehicle simulation model can be generally classified as two types: kinematic and dynamic methods. In the kinematic method, the force required to accelerate the vehicle through the time step is calculated directly from the required speed trace. The required force is then translated into a torque that must be provided by the component directly upstream. This power/energy requirement at the wheel is passed backward through all the power train components to compute fuel and electricity consumption. The dynamic method is solved forward approach where the desired vehicle speed is an input to the driver/PID controller which actuates the accelerator position therefore requesting torque from the engine which in turn produces a response through the driveline. This method is more realistic in that it controls the engine similar to the way an actual driver does and does not impose or directly control the driveline components. The tuning of the driver/PID determines how accurately the analytical vehicle follows the desired vehicle speed trace. Although both kinematic and dynamic methods were evaluated in this project, it was determined that the dynamic method produced the most realistic results.

The GT-Drive software [15] was used for the analytical simulation in this project. For this study a relatively simple approach was taken that uses steady-state engine performance maps to determine fuel rate for a desired engine torque at a given engine speed. It has been shown that fuel economy can be accurately predicted using simple steadystate engine maps [16, 17]. For accurate simulation, the model also requires significant driveline information: clutch and torque converter performance tables; transmission with 


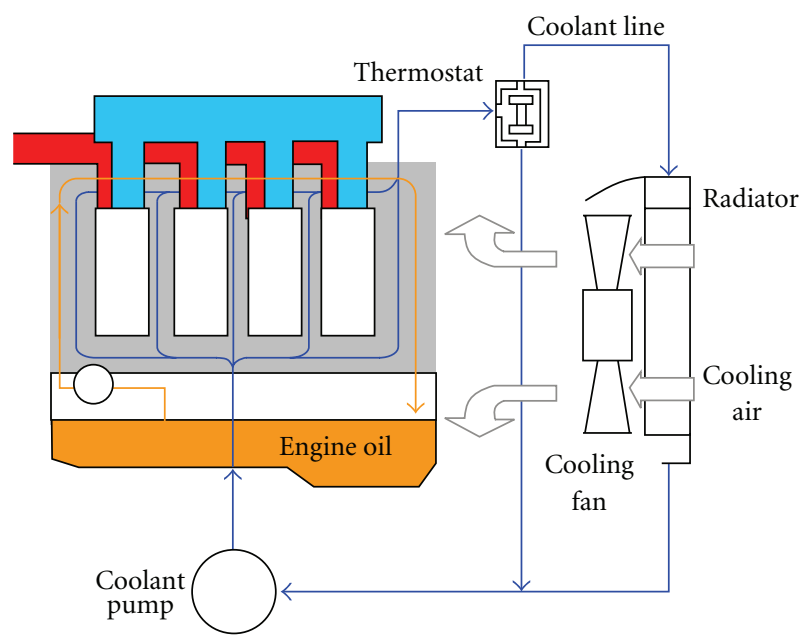

(a) Schematic diagram of diesel engine with its cooling system

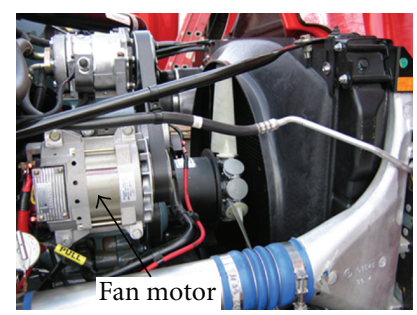

(b) Single motor fan

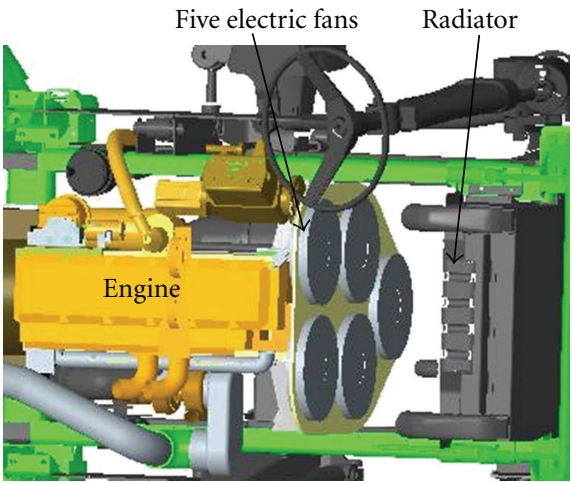

(c) Five motor fans

FIGURE 2: Arrangements of electric fans.

gear ratios, inertias, efficiencies and shift schedule; transfer case with gear ratio, inertias and torque split percentage between front and rear axle; drive shaft and axle with inertias; final drive with gear ratio and inertias; tires with radius, rolling resistances and any traction-limit data; brake with braking torque maps and any other data related to vehicle resistances such as aerodynamic loading. Other control components were added to the model to simulate an idle speed controller and a simple fuel shut-off control during deceleration events; producing more accurate simulation of actual operating conditions. A layout GT-Drive model is presented in Figure 3.

3.2. Baseline Vehicle Experimental Test. Experimental test was performed to collect real-world vehicle data to correlate and validate the analytical vehicle model. Coast downtesting and fuel economy drive cycle was performed. The test vehicle was instrumented to collect among other information: engine speed, vehicle speed, accelerator pedal position, manifold pressure, gear position, fuel flow rate, and wind speed and direction. The wind sensor assembly was mounted $3 \mathrm{~m}$ in front of the vehicle at approximate half its height $(1.4 \mathrm{~m})$. This was done in order to place the wind speed/direction measuring device in an area where it is not influenced by the boundary layer created around the moving vehicle. The tripod-like frame that sustains the wind sensor assembly was made in such way that its contribution to the overall aerodynamic drag is minimized. Instrumented vehicle test weight and daily weather data were also acquired. The baseline vehicle instrumentation is shown in Figure 4.
3.2.1. Coast Downtesting. Coast downtesting was performed to establish the drag forces that act on the vehicle. In this method the vehicle is accelerated to a desired speed, transmission set to neutral gear and then allowed to decelerate under the action of various drag forces. The general form of the equation of motion is:

$$
M_{e} \cdot \frac{d V_{\mathrm{veh}}}{d t}=D_{r}+D_{a}+D_{g}
$$

where $M_{e}$ is effective vehicle mass, $V_{\text {veh }}$ is vehicle speed $(\mathrm{km} / \mathrm{h}), D_{r}$ is rolling resistance force, $D_{a}$ is aerodynamic drag force, and $D_{g}$ is gravity force

$$
M_{e}=M_{\mathrm{veh}}+\frac{I_{f}+I_{r}}{R^{2}},
$$

where $M_{\mathrm{veh}}$ is vehicle mass $(\mathrm{kg}), I_{f}$ and $I_{r}\left(\mathrm{~kg} \mathrm{~m}^{2}\right)$ is the moment inertia for the front and rear axle, respectively, and $R$ is tire rolling radius $(\mathrm{m})$. The rolling resistance force is calculated as a second-degree function of vehicle speed.

$$
D_{r}=\alpha_{r}+\beta_{r} \cdot V_{\mathrm{veh}}+\gamma_{r} \cdot V_{\mathrm{veh}}^{2},
$$

where $\alpha_{r}, \beta_{r}$, and $\gamma_{r}$ are rolling resistance coefficients. The aerodynamic drag is calculated as a fourth degree function of yaw angle and second-degree relative wind speed

$$
\begin{aligned}
D_{a}= & \frac{1}{2} \cdot p_{\text {air }} \cdot A_{\text {frontal }} \cdot V_{w}^{2} \\
& \cdot\left(a_{0}+a_{1} \cdot Y+a_{2} \cdot Y^{2}+a_{3} \cdot Y^{3}+a_{4} \cdot Y^{4}\right),
\end{aligned}
$$

where $p_{\text {air }}$ is air density, $A_{\text {frontal }}$ is frontal area, $V_{w}$ is relative wind speed $(\mathrm{km} / \mathrm{h}), Y$ is wind yaw angle, $a_{0}, a_{1}, a_{2}, a_{3}$, and 


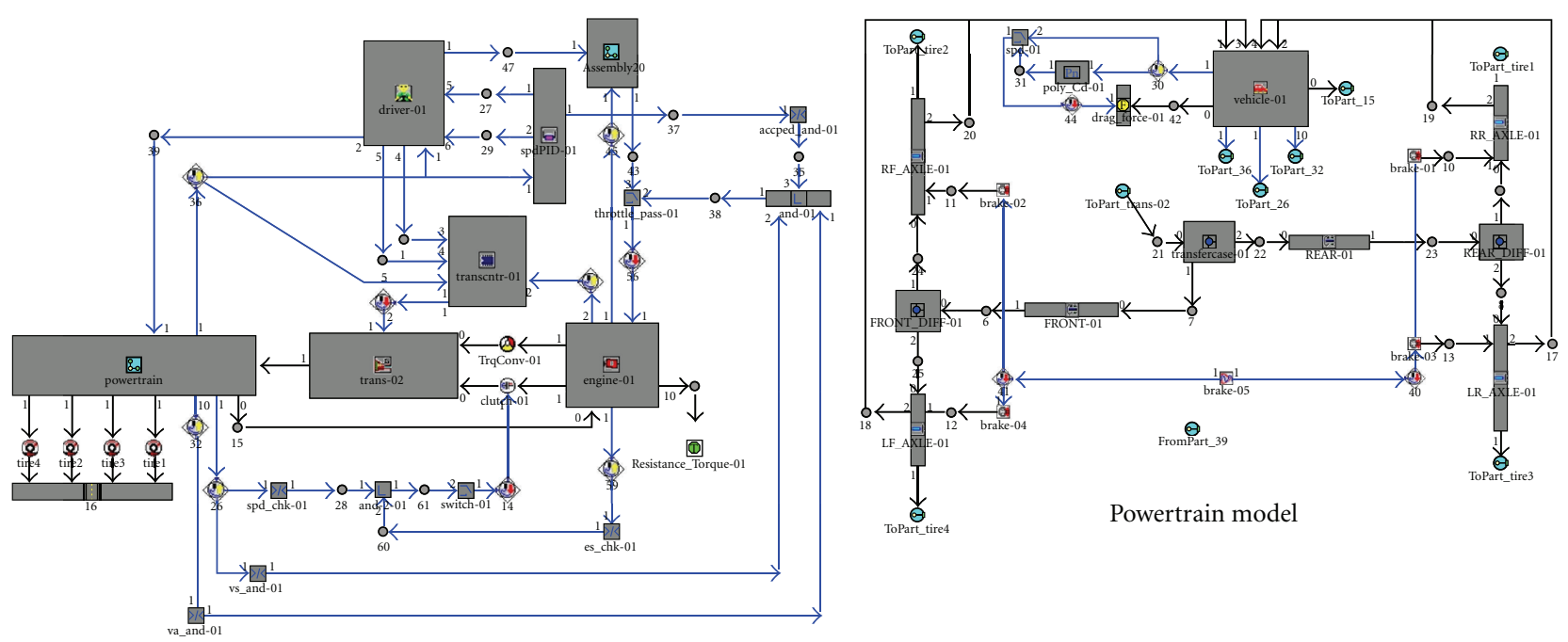

FIGURE 3: GT-Drive model of the conventional M1078 truck.
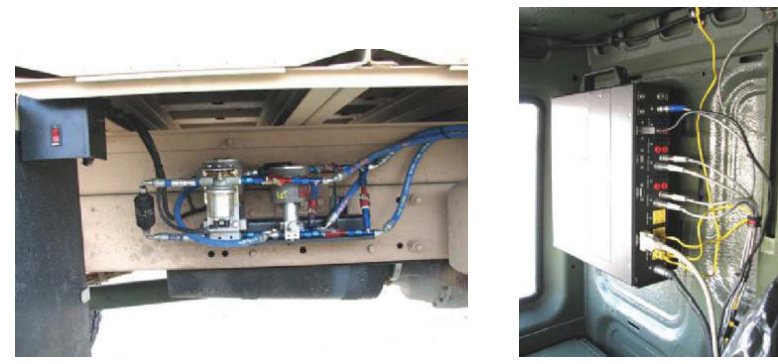

Fuel flow meter installation

Data acquisition instrumentation

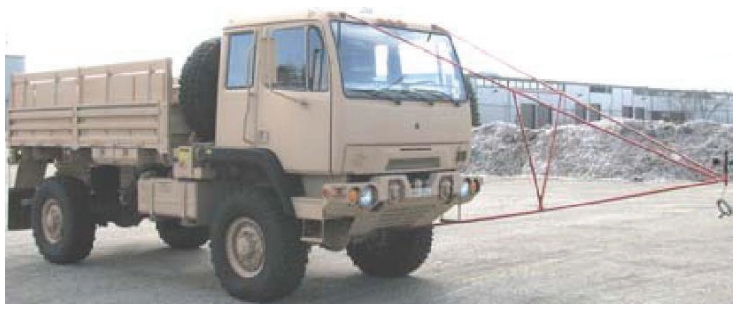

Wind sensor installation

FIGURE 4: Vehicle instrumentation.

$a_{4}$ are aerodynamic drag coefficients. The gravitational is a function of slope and vehicle mass

$$
D_{g}= \pm M_{e} \cdot g \cdot \frac{d h}{d L},
$$

where $g$ is acceleration of gravity, $h$ is the height, and $L$ is the horizontal traveling distance.

3.2.2. Driving Cycle. This project adopts the driving cycle of $[14,18]$ which is created from portions of the Munson Road course at the Aberdeen Proving Ground and a modified U.S. Environmental Protection Agency (EPA) driving schedule [19]. Shown in Figure 5, a typical mission schedule of the LMTV includes the beginning segments of varying vehicle speed over flat terrain with frequent accelerations and decelerations (the primary and secondary roads), and then a segment with varying grades at a constant vehicle speed (cross-country road). This mission schedule consists of $50 \%$ secondary roads, $20 \%$ primary roads, and $30 \%$ crosscountry.

3.3. Fuel Economy Correlation between Simulation and Experimental Baseline Vehicle. An experimental mean data was calculated for fuel economy comparison which was simply the average of all experimental test data. The end of cycle difference between experimental and baseline analytical model is 113.87 grams. This translates into a fuel economy difference of $0.012 \mathrm{liter} / \mathrm{km}$ as the simulation result of 3921.26 grams translates to 0.386 liter $/ \mathrm{km}$ $(6.09 \mathrm{mi} / \mathrm{gal})$ and the experimental average of 3807.39 grams translates to $0.375 \mathrm{liter} / \mathrm{km}(6.27 \mathrm{mi} / \mathrm{gal})$. The simulation fuel economy result falls within the variation of the experimental data: the minimum experimental result was 0.406 liter $/ \mathrm{km}(5.79 \mathrm{mi} / \mathrm{gal})$ and maximum was 0.356 liter/ $\mathrm{km}(6.61 \mathrm{mi} / \mathrm{gal})$. The simulation underestimates fuel economy by $2.87 \%$. The natural thought of this discrepancy would be a road load error at higher vehicle speeds. But even with drastic reductions in higher speed road loads, the required analytical torque was still appreciably higher than the experimental average. Based on this correlation, the predicted fuel economy from GT-Drive simulation is quite acceptable for the baseline vehicle.

3.4. Simulation Results of Mid-Term Integration. The purpose of establishing a validated baseline vehicle simulation model is to use its high fidelity simulation result as a base for integrated technologies and hybrid propulsions comparison. The fuel economy improvements on integrated technologies and hybrid propulsions use this simulation data (on conventional vehicle) as a comparison base. For componentlevel modelling (such as electric fans), a composite sum of 


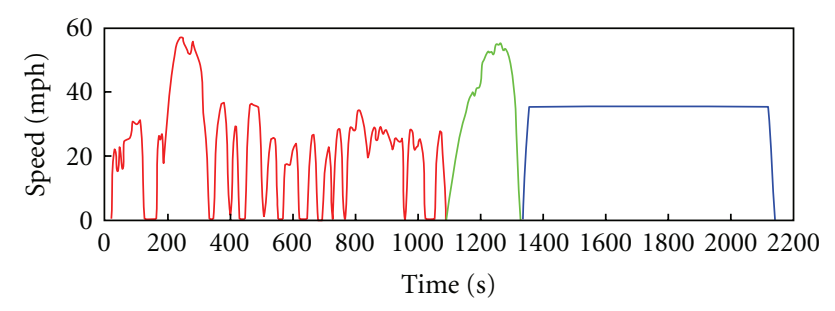

(a) Vehicle speed trace

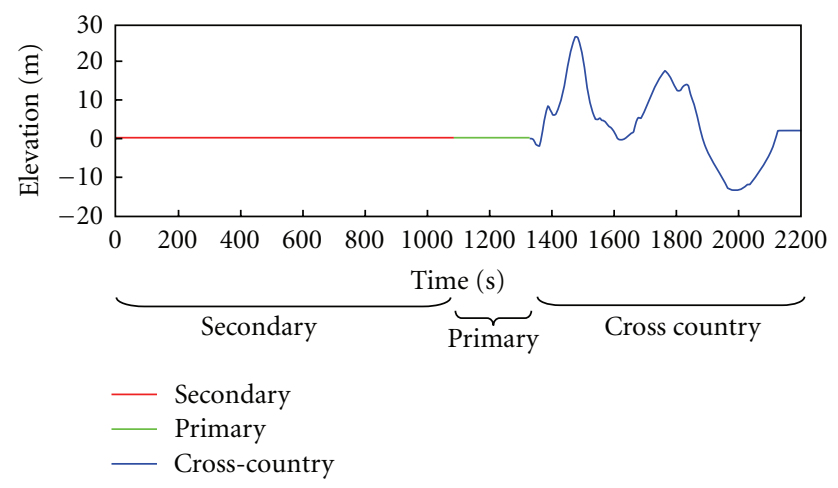

(b) Elevation trace

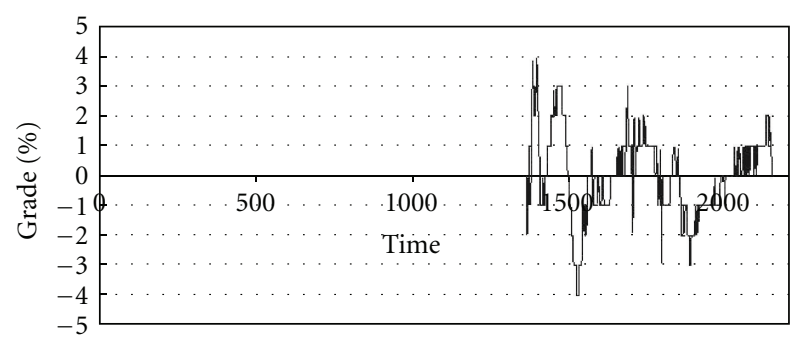

(c) Elevation trace in grade

Figure 5: LMTV typical mission schedule (50\% secondary, 20\% primary, and $30 \%$ cross-country roads) [14].

electrical and mechanical accessory loads was adjusted to correspond with the changes on electric and engine loads.

The simulation result of the M1078 with the electric fans shows a 3.3\% improvement in fuel economy when compared to the base model. An integrated automatic engine stop/start system shows a 3.4\% improvement in fuel economy. A BeltAlternator-Starter (BAS) system [20, 21] or Belt-IntegratedStarter-Generator (B-ISG) [22], modified to include an automatic stop/start system and full accessory electrification is the recommended mild hybridization technology for midterm integration. Simulation result of this system integrated into an M1078 indicates a 10.2\% improvement in fuel economy when compared to the base model.

\section{Experimental Investigation of Hydrogen Injection}

This experimental test investigated the effectiveness of supplementary small volume hydrogen injection for turbo diesel engine application. This is a preliminary study with the primary focus on determining if this technology merits further and more elaborate investigation.

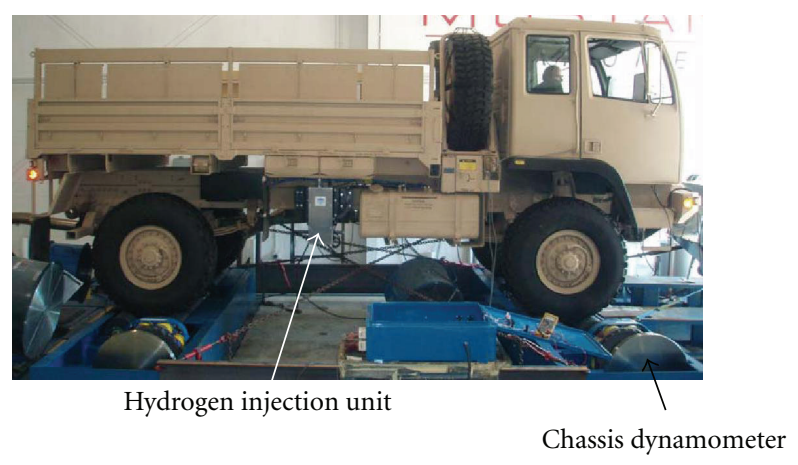

Figure 6: Chassis dynamometer test.

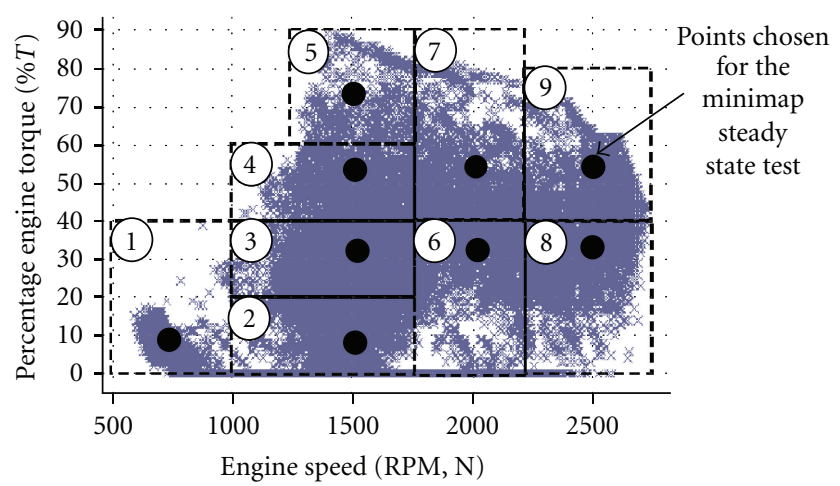

Figure 7: Scatter plot of \% engine torque versus speed (unfiltered complete dataset).

The test vehicle was instrumented to collect among others: $\mathrm{H}_{2}$ flow, $\mathrm{H}_{2}$ pressure, engine speed, vehicle speed, accelerator pedal position, manifold pressure, fuel flow rate, and so forth. The data acquisition system also interfaced with the chassis dynamometer to collect data corresponding to roll speed and roll torque as shown in Figure 6. In order to measure the power consumed by the electrolysis process, the unit was instrumented for amperage and voltage using two shunts that were installed near the alternator to measure the current in the $12 \mathrm{~V}$ and $24 \mathrm{~V}$ circuits. Steady state test points, or minimap, were used in chassis dynamometer to evaluate the potential fuel economy improvement of the $\mathrm{H}_{2}$ injection system. Weight factors applied to these points were based on residency time in the Urban Dynamometer Driving Schedule (UDDS). Fuel consumption was measured at these points with weight factor and converted into fuel economy in both hydrogen injection unit on and off conditions.

The steady-state test points were determined from vehicle experimental data in UDDS. The unfiltered experimental data from two tests were combined and analyzed for vehicle operating at particular engine percentage torque and speed. The combined data consists of 127354 points. Figure 7 illustrates the percentage of torque versus speed scatter plot for minimap point determination. The minimap defines engine operating characteristics over a small operating range around some desired point, which provides a physics-based estimate of engine performance $[23,24]$. Each point in the 
TABLE 3: Fuel economy data of $\mathrm{H}_{2}$ injection test.

(a)

\begin{tabular}{|c|c|c|c|c|c|c|c|c|c|c|c|c|c|}
\hline \multirow[b]{3}{*}{ RPM } & \multirow[b]{3}{*}{$\% \mathrm{~T}$} & on & \multicolumn{11}{|c|}{ Total distance: $149.686 \mathrm{~km}$ Total fuel: 58.2 liter Fuel economy: 0.389 liter $/ \mathrm{km}(6.049 \mathrm{mi} / \mathrm{gal})$} \\
\hline & & \multirow{2}{*}{$\begin{array}{l}\text { Average } \\
\text { fuel rate } \\
\text { Liter/hr }\end{array}$} & \multirow{2}{*}{$\begin{array}{l}\text { Total fuel } \\
\text { Liter }\end{array}$} & \multicolumn{2}{|c|}{ Test 1} & \multicolumn{2}{|c|}{ Test 2} & \multicolumn{2}{|c|}{ Test 3} & \multicolumn{2}{|c|}{ Test 4} & \multicolumn{2}{|c|}{ Test 5} \\
\hline & & & & $\begin{array}{l}\text { Fuel } \\
\text { rate }\end{array}$ & $\begin{array}{l}\text { Roll } \\
\text { torque }\end{array}$ & $\begin{array}{l}\text { Fuel } \\
\text { rate }\end{array}$ & $\begin{array}{l}\text { Roll } \\
\text { torque }\end{array}$ & $\begin{array}{l}\text { Fuel } \\
\text { rate }\end{array}$ & $\begin{array}{l}\text { Roll } \\
\text { torque }\end{array}$ & $\begin{array}{l}\text { Fuel } \\
\text { rate }\end{array}$ & $\begin{array}{l}\text { Roll } \\
\text { torque }\end{array}$ & $\begin{array}{l}\text { Fuel } \\
\text { rate }\end{array}$ & $\begin{array}{l}\text { Roll } \\
\text { torque }\end{array}$ \\
\hline 750 & 10 & 3.467 & 2.848 & 2.79 & 134.5 & 3.81 & 134.31 & 3.66 & 135.09 & 2.86 & 134.2 & 3.85 & 135.47 \\
\hline 1500 & 10 & 6.372 & 5.768 & 6.48 & 142.02 & 6.37 & 143.43 & 6.29 & 143.81 & 6.66 & 142.54 & 6.01 & 149.92 \\
\hline 1500 & 30 & 19.452 & 10.315 & 20.16 & 373.82 & 19.05 & 376.87 & 19.02 & 377.45 & 20.45 & 374.82 & 19.15 & 377.76 \\
\hline 1500 & 50 & 29.685 & 8.449 & 29.66 & 631.74 & 30.19 & 641.4 & 29.33 & 643.33 & 29.49 & 640.74 & 29.73 & 635.34 \\
\hline 2000 & 30 & 26.007 & 10.689 & 26.35 & 351.22 & 25.37 & 357.57 & 24.79 & 351.62 & 26.18 & 353.63 & 28.13 & 345.57 \\
\hline 2000 & 50 & 39.482 & 5.280 & 40.61 & 642.1 & 38.73 & 640.25 & 38.52 & 650.06 & 39.26 & 646.12 & 40.7 & 651.13 \\
\hline 2500 & 30 & 32.923 & 14.863 & 31.87 & 248.47 & 32.1 & 263.93 & 30.11 & 251.77 & 34.77 & 252.59 & 36.65 & 246.81 \\
\hline
\end{tabular}

(b)

\begin{tabular}{|c|c|c|c|c|c|c|c|c|c|c|c|c|c|}
\hline \multicolumn{3}{|c|}{$\mathrm{H}_{2}$ injection off } & \multicolumn{11}{|c|}{ Total distance: $149.686 \mathrm{~km}$ Total fuel: 56.9 liter Fuel economy: 0.380 liter $/ \mathrm{km}(6.186 \mathrm{mi} / \mathrm{gal})$} \\
\hline \multirow[b]{2}{*}{ RPM } & \multirow[b]{2}{*}{$\% \mathrm{~T}$} & \multirow{2}{*}{$\begin{array}{l}\text { Average } \\
\text { fuel rate } \\
\text { Liter/hr }\end{array}$} & \multirow{2}{*}{$\begin{array}{l}\text { Total fuel } \\
\text { Liter }\end{array}$} & \multicolumn{2}{|c|}{ Test 1} & \multicolumn{2}{|c|}{ Test 2} & \multicolumn{2}{|c|}{ Test 3} & \multicolumn{2}{|c|}{ Test 4} & \multicolumn{2}{|c|}{ Test 5} \\
\hline & & & & $\begin{array}{l}\text { Fuel } \\
\text { rate }\end{array}$ & $\begin{array}{l}\text { Roll } \\
\text { torque }\end{array}$ & $\begin{array}{l}\text { Fuel } \\
\text { rate }\end{array}$ & $\begin{array}{l}\text { Roll } \\
\text { torque }\end{array}$ & $\begin{array}{l}\text { Fuel } \\
\text { rate }\end{array}$ & $\begin{array}{l}\text { Roll } \\
\text { torque }\end{array}$ & $\begin{array}{l}\text { Fuel } \\
\text { rate }\end{array}$ & $\begin{array}{l}\text { Roll } \\
\text { torque }\end{array}$ & $\begin{array}{l}\text { Fuel } \\
\text { rate }\end{array}$ & $\begin{array}{l}\text { Roll } \\
\text { torque }\end{array}$ \\
\hline 750 & 10 & 2,976 & 2.445 & 2.78 & 134.51 & 2.81 & 134.88 & 2.8 & 136.07 & 2.94 & 130.51 & 3.55 & 131.88 \\
\hline 1500 & 10 & 6.342 & 5.741 & 6.67 & 142.5 & 6.42 & 146.12 & 6.14 & 144.11 & 6.60 & 139.27 & 5.88 & 140.21 \\
\hline 1500 & 30 & 19.698 & 10.446 & 20.09 & 376.15 & 19.84 & 376.91 & 19.66 & 377.55 & 19.85 & 371.89 & 19.05 & 375.08 \\
\hline 1500 & 50 & 29.564 & 8.414 & 29.48 & 640.75 & 29.55 & 639.06 & 29.66 & 637.35 & 30.18 & 633.47 & 28.95 & 617.69 \\
\hline 2000 & 30 & 25.576 & 10.512 & 25.53 & 351.91 & 25.41 & 351.96 & 25.21 & 351.84 & 26.47 & 350.76 & 25.26 & 351.61 \\
\hline 2000 & 50 & 38.966 & 5.211 & 39.07 & 649.07 & 39.01 & 651.39 & 39.12 & 652.49 & 39.06 & 638.37 & 38.57 & 641.94 \\
\hline 2500 & 30 & 31.350 & 14.143 & 30.29 & 253.76 & 32.14 & 250.31 & 31.1 & 256.47 & 31.97 & 249.73 & 31.25 & 255.61 \\
\hline
\end{tabular}

graph represents one data sample at $0.1 \mathrm{sec}$ increments. The dot marks indicate points (at specific percentage of torque and speed) chosen for the minimap steady-state testing. Once the steady-state test points were identified with weight factors, the next step was to analyze the chassis dynamometer roll tests. The chassis roll tests were intended to operate the engine at the specific percentage of torque and speed which were indicated on test points noted above. The data were filtered to eliminate transients such as changes in roll torque, roll power, and cooling fan on/off condition (preferred cooling fan off condition for data analysis). For all the minimap points, an attempt was made to match the roll torques as close as possible, even though this may imply a different percentage of torque from the controller unit. This intent was to provide a consistent comparison of fuel consumption for the $\mathrm{H}_{2}$ injection unit on versus off condition.

The resultant fuel economy presented in Table 3 was an equalization of roll torque. The equalized roll torque was particularly important at the $10 \%$ torque points with 700 and $1500 \mathrm{rpm}$ speed. For these points in particular as well as the remaining minimap points were taken priority over entries at the same percentage of engine torque. The fuel economy was $0.389 \mathrm{liter} / \mathrm{km}(6.049 \mathrm{mi} / \mathrm{gal})$ with the $\mathrm{H}_{2}$ injection unit $\mathrm{ON}$ and $0.380 \mathrm{liter} / \mathrm{km}(6.186 \mathrm{mi} / \mathrm{gal})$ with the unit OFF. This represents a decrease in fuel economy of $2.28 \%$. Based on these results, it is concluded that the on-board $\mathrm{H}_{2}$ generation system produces no measurable improvement in fuel economy over the UDDS. It could easily be argued that the additional electrical load, about 10 amps, while the unit was running actually caused the fuel economy to degrade.

\section{Conclusion}

The focus of this project is the feasibility analysis and evaluation of current and future technology offerings from original equipment manufacturers and aftermarket suppliers that improve the fuel economy of the medium-duty tactical trucks. A strategic plan, preliminary modeling and simulation, and experimental results are reported in this paper.

The strategic plan lays out the integrated technologies in the near-term including auxiliary electrification of engine cooling fan and hydrogen injection into the engine air intake. For the mid-term time frame, the plan involves implementing an engine stop/start system and electrifying other auxiliaries. The final step in the plan is the development and implementation of a full (strong) hybrid population. This paper presented the preliminary results of (1) establishing a validated, high fidelity baseline analytical vehicle 
model, (2) modelling and simulation of the electrified engine cooling fan and mild hybrid power train system, and (3) experimental investigation of the influence of hydrogen injection on fuel economy.

Experimental test was performed to correlate and validate the analytical vehicle model. Based on the correlation, the predicted fuel economy from simulation is quite acceptable. Then the fuel economy improvements on integrated technologies and hybrid propulsions use this high fidelity simulation data (on conventional vehicle) as a comparison base. Simulation of the electric fans shows an estimated 3.3\% improvement in fuel economy when compared to the base model. Mid-term integration of a stop/start system followed by a B-ISG mild hybrid system incorporating regenerative braking is estimated to improve fuel economy 3.39\% and $10.2 \%$, respectively. Other experimental test was conducted to investigate the effectiveness of supplementary small volume hydrogen injection for turbo diesel engine application. The test data indicated a decrease in fuel economy of $2.28 \%$ for the on-board $\mathrm{H}_{2}$ generation system over the UDDS.

In this planning and preliminary evaluation stages, a strategic plan, vehicle simulation model, experimental validation and test were developed. The simulation software is utilized to analyze the component packaging, model and predict the vehicle fuel economy improvement. The further hardware implementation, system validation, and proving ground evaluation will be the future work.

\section{Acknowledgments}

The authors would like to acknowledge the technical and financial support of the National Automotive Center (NAC) located within the U.S. Army Tank-Automotive Research, Development and Engineering Center (TARDEC). In particular, Paul Skalny at NAC provided technical guidance related to the LMTV fuel saving program goals, and Matt Van Benschoten in Roush Industry conducted the experiments. Finally, the authors would like to thank the management of World Technical Services, Inc., ASRC Federal Holding Company, for their support of this paper.

\section{References}

[1] U.S. Department of Defense, More Capable War Fighting through Reduced Fuel Burden, Office of the Under Secretary of Defense for Acquisition, Technology and Logistics, Washington, DC, USA, 2001.

[2] V. Muradian, "Interview with terry pudas, acting deputy assistant secretary of defense for forces, transformation and resources," Defense News, 2007.

[3] S. Karbuz, "US military energy consumption-facts and figures," Energy Bulletin, 2011, http://www.energybulletin.net/ node/29925.

[4] BAE Systems, 2011, http://www.baesystems.com/ProductsServices/bae_mps_prod_fmtv.html.

[5] U.S. Department of Energy, "Technology roadmap for the 21st century truck program: a government-industry research partnership," Tech. Rep., Information Bridge: DOE Scientific and Technical Information, Office of Scientific and Technical Information, 2000, http://www.osti.gov/bridge/ servlets/purl/777307-BKSUFs/native/777307.pdf/.

[6] BAE Systems, 2011, http://www.baesystems.com/BAEProd/ groups/public/documents/bae_publication/bae_pdf_mps_ fmtv_m1078a1.pdf.

[7] U.S. Army, "Office of the deputy assistant secretary of the army for research and technology," Army Science \& Technology Master Plan, I-9, Washington, DC, USA, 2007.

[8] U.S. National Academy of Sciences, "Tires and passenger vehicle fuel economy," Transportation Research Board Special Report 286, Washington, DC, USA, 2006.

[9] S. Elliot-Sink, "Improving Aerodynamics to Boost Fuel Economy," Edmunds, 2011, http://www.edmunds.com/fuel-economy/improving-aerodynamics-to-boost-fuel-economy.html? articleid $=106954 \&$.

[10] M. Johannaber and M. Espig, "Determination of weight elasticity of fuel economy for conventional ICE vehicles, hybrid vehicles and fuel cell vehicles," International Iron and Steel Institute, Middletown, Ohio, USA, 2007.

[11] Lear Corporation and SoyFoam, 2011, http://www.lear.com/ en/seating/foam.aspx.

[12] Autotherm, Enthal Systems, Inc, 2011, http://www.autothermusa.com.

[13] VTM, Variable Torque Motors, LLC, 2011, http://variabletorquemotors.com.

[14] Z. Filipi, L. Louca, A. Stefanopoulou et al., "Fuel cell APU for silent watch and mild electrification of a medium tactical truck," SAE Paper 2004-01-1477, 2004.

[15] GT-Drive, Gamma Technologies, Inc, Westmont, Ill, USA, 2004, http://www.gtisoft.com.

[16] S. Hausberger and M. Rexeis, "Emission behaviour of modern heavy duty vehicles in real world driving," International Journal of Environment and Pollution, vol. 22, no. 3, pp. 275-286, 2004.

[17] M. Ward, C. Brace, T. Hale, and R. Ceen, "Investigation of sweep mapping approach on engine testbed," SAE Paper 200201-0615, 2002.

[18] R. W. Page, W. Hnatczuk, and J. Kozierowski, “Thermal management for the 21 century-improved thermal control and fuel economy in an army medium tactical vehicle," SAE Paper 2005-01-2068, 2005.

[19] U.S. EPA, Environmental Protection Agency, "Testing and measuring emissions," 2011, http://www.epa.gov/nvfel/testing/dynamometer.htm.

[20] R. R. Henry, B. Lequesne, S. Chen et al., "Belt-driven starter generator for future 42-volt systems," SAE Paper 2001-010728, 2001.

[21] H. Kusumi, K. Yagi, Y. Ny et al., "42V power control system for mild hybrid vehicle (MHV),” SAE Paper 2002-01-0519, 2002.

[22] M. Canova, K. Sevel, Y. Guezennec, and S. Yukovich, "Control of the start/stop of a diesel engine in a parallel HEV with a belted starter/alternator," SAE Paper 2007-24-0076, 2007.

[23] M. Ward, C. Brace, T. Hale, and R. Ceen, "Investigation of sweep mapping approach on engine testbed," SAE Paper 200201-0615, 2002.

[24] H. B. Pacejka, Tyre and Vehicle Dynamics, ButterworthHeineman, Oxford, UK, 2nd edition, 2002. 

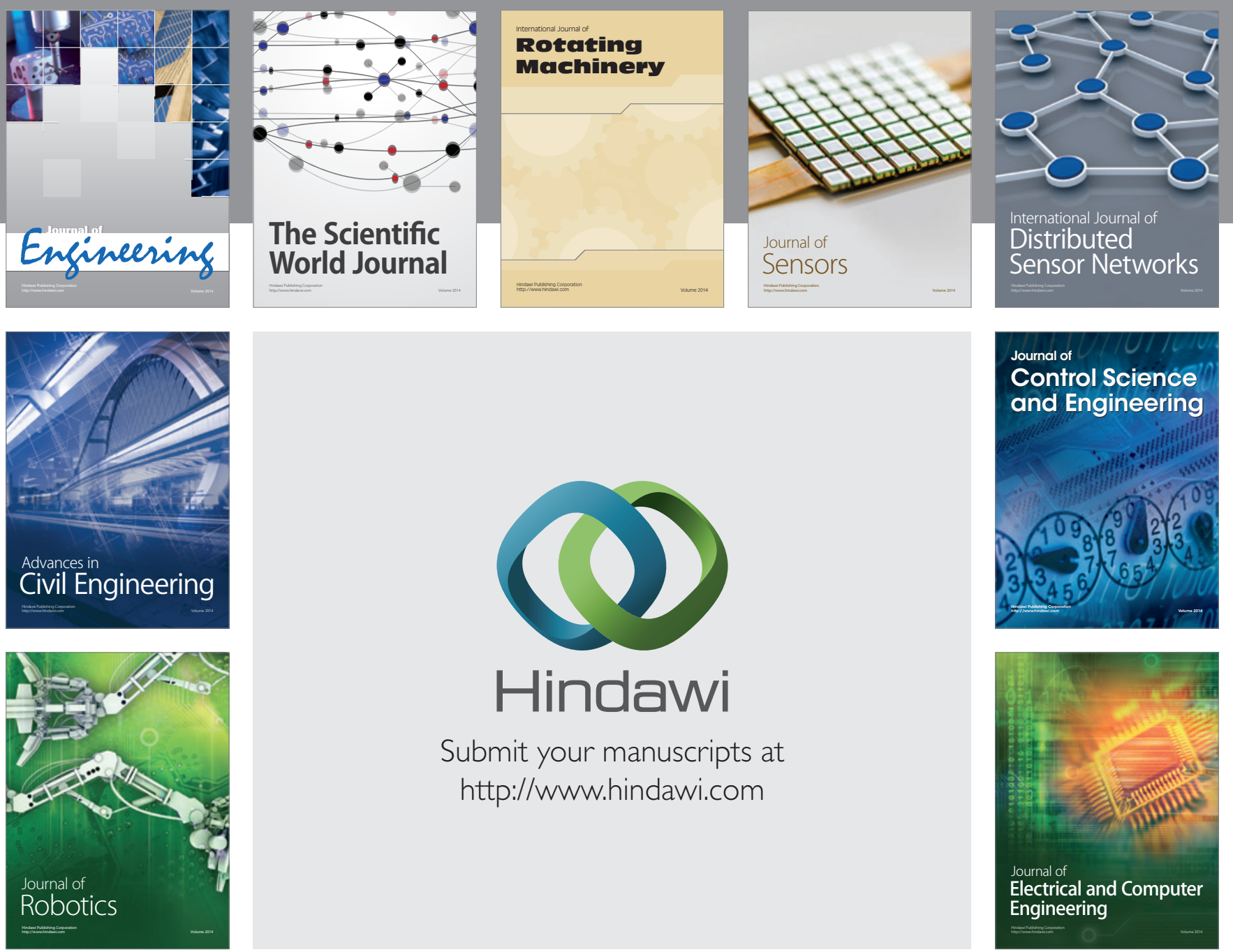

Submit your manuscripts at

http://www.hindawi.com
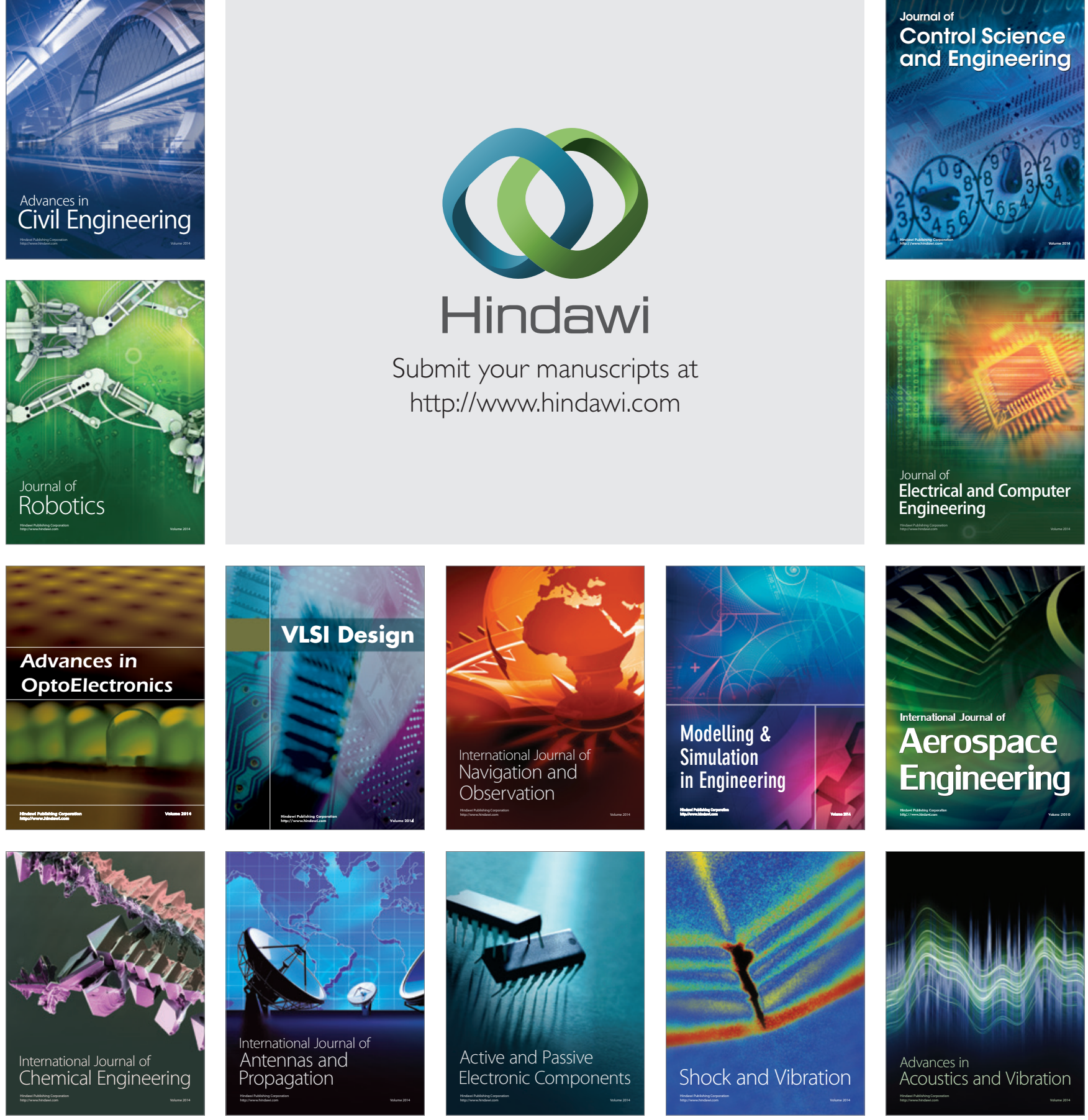